\title{
Network Based Production System Architecture
}

\author{
E. Arai
}

Dept. of Manufacturing Science, Graduated School of Eng., Osaka Univ. 2-1, Yamadaoka, Suita, Osaka 565-0871, Japan

Phone: +81-6-879-7555, Fax: +81-6-879-7570

\section{Takata}

Information Processing Center, The University of Electro-Communications 1-5-1, Chofugaoka, Chofu, Tokyo 182, Japan Phone: +81-424-83-2161(ex.4744), Fax: $+81-424-84-1598$

\footnotetext{
ABSTRACT

The aim of this paper is to point value of auction in hierarchical manufacturing system architecture. "Auction" is an interrelation of computer systems and cells, and, also cells and stations, in which active database assigns certain jobs to the cells, and the cells judge their ability to do the assigned jobs. The cells deliver the required jobs to the stations also via active database, and the stations judge their ability too with calculation of estimated machining time. The cells estimate the machining time according to the most adequate usage of the stations, and hierarchically they are reported to the scheduling system. The final result comes as the selection of minimum machining time by the computer system. It is efficient, for cells are given ability to estimate their possibility in achieving jobs, and therefore the total system acts pliably.
} 
It is true that interrelation between the scheduling systems and the cells has been achieved in conventional manufacturing systems, but the systems have predominated over the actual cells. In those systems, job information has been provided by the systems and the cells have remained subordinate. However, recent advancement of the cell controllers and station controllers has enabled to administer intelligent information processing even within the cells and stations. Cell and station controllers may judge possibility to accomplish assigned jobs, generate operation plan, and estimate machining time.

Therefore, this hierarchical manufacturing system architecture, called "auction" should play a key role in re-scheduling in order to cope with potential alteration.

\section{Keywords}

distributed manufacturing system, dynamic scheduling, production scheduling, active database, machining features, flexible features, CAD, CAM

\section{INTRODUCTION}

Levels of automation have been achieved to enhance the efficiency in production as synthesis of CAD/CAM systems, automated facilities and scheduling systems. $\mathrm{CAD} / \mathrm{CAM}$ have predominated over production process, and alteration has taken place in CAD/CAM even if modification has been required in the actual production process. Therefore, this system is unprotected against potential failures, such as sudden change in production plan or failures of facilities.

In order to cope with these problems, distributed manufacturing system with the help of "auction" is effective[Arai, E., (1995)]. Hierarchical architecture among the total system, the cells and the stations add more flexibility when the cells behave independent of each other. Some of controlling features, such as operation planning, are given to hardwares of machine tools and robots. These controllers are connected in computer networks, and specific problems are dealt in a network architecture based on active database system. Final results are given as modification of production plan through scheduling system.

\section{SYSTEM ARCHITECTURE}

Interrelationship between the scheduling system and the cells is vital element to achieve pliable production plans[Okuno, N., (1992)][Ueda, K., (1992)]. A case of distributed production system based on active database is shown here to explain 
actual procedures in assigning jobs to the cells, and also from the cells to the stations with the help of auction(Figure 1).

First, the production requirements are delivered to the cells. The core part of this renovating system is the combination of communication controllers and job/cell databases in a network system. The job database stores the production requirements, and the cell database stores the functionality and the current status of machining cells that is kept updated.

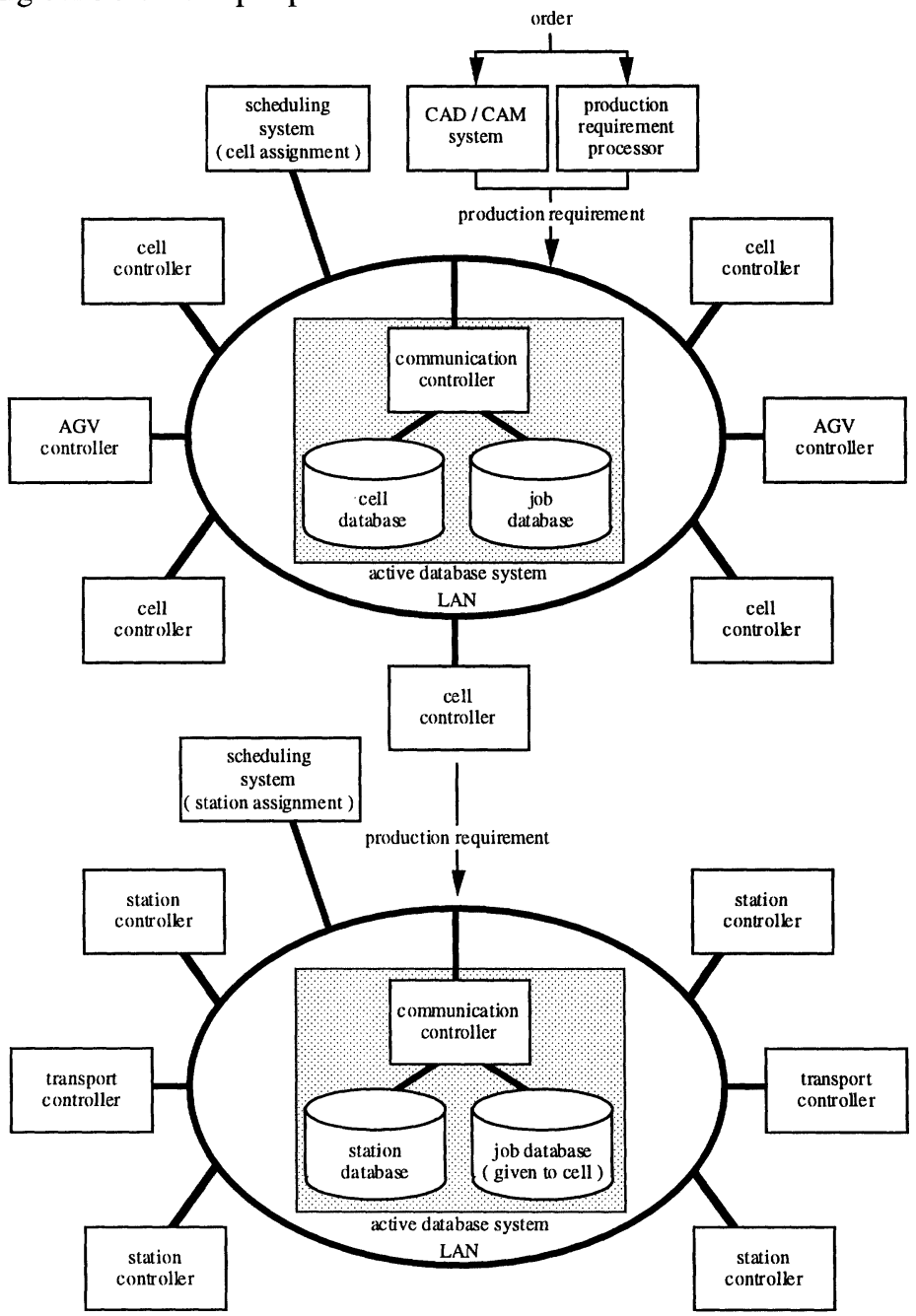

Figure 1 Auction based system architecture with active database. 


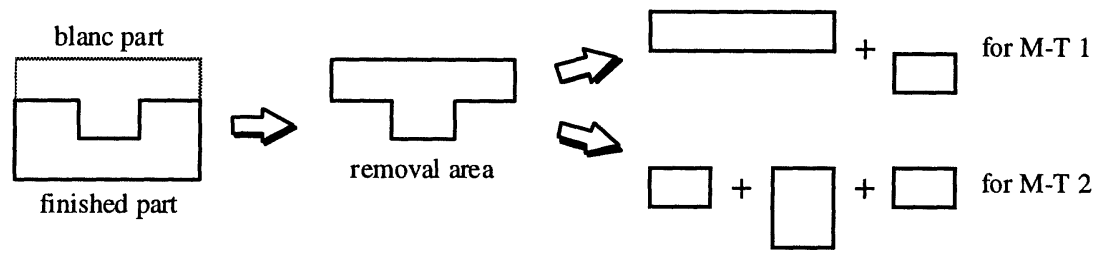

Figure 2 Different operations for the same removal area.

In a surrounding area, production scheduling system and CAD/CAM systems are connected to the core part. (Material handling system is not considered here).

Actual machining cells are connected also in this surrounding area. Generally production of parts requires specification of kinds and numbers. (Due dates are not considered at this point.). Details of parts are described in the CAD system using machining features with procedure constraints extracted through recognition process in the CAM system[Ranky, P. G., (1992)][Kjellberg, T., (1991)]. Functionality of machining cells are characterized by feature classes, accuracies and maximum dimensions, and they are kept updated through the network. These informations are the basis for the auction.

Therefore, at this point "auction" plays an important role. For one assignment of carving, for example, various operation plans may be presented (Figure 2), but intelligent machining cells can make their own operation decisions by selecting the most suitable. Definite production requirements are transmitted to the job database when they become determined.

Hierarchically, each cell has the active database system and the scheduling system to assign the job to the belonging stations. The station database connects to the active database instead of the cell database mentioned above. Functionality of stations are also characterized by machining feature classes, accuracies and maximum dimensions. The production requirements that are delivered from the production systems to the selected cells are passed though to the selected stations via active database within the cells.

\section{PRODUCTION SCHEDULING}

Production requirements are given to the production system when it is initialized and are sent to the active database. Production requirements consist of the product representation which is a set of "flexible features" mentioned in the next section, required number, and the due date for each product ordered. The active database stores them in the job database, and deliver each of them to the selected cells that 
are feasible for machining each product based on the functionality and status referring to the cell database.

Repeatedly the cell controller passes through the given production requirements to the active database within the cell that decompose them into more detailed machining processes, and deliver each of them to the selected stations referring to the station database.

Station controllers calculate the machining time for given processes and reply the estimated machining time to the active database. Collected estimations are sent to the scheduling system where the machining processes are assigned to the stations. The cell controller calculates the total processing time to accomplish the production requirement according to the scheduling system within the cell, and report it to the active database of the production system where necessary replies from the cells are collected and sent to the scheduling system of the production system. The cell assignment is executed there.

There is another important element in the system that is "triggers" to run the system. The active database can be elaborated when "triggers" occur.

Production schedule must be pliably altered when "triggers", or modifying elements, are found[Takata, M., (1995)]. In active database, triggers are changes in production plans, and in cells, stations, or AGVs they are changes in functionality, such as failures, recovery or renewal.

Three types of triggers are considered ; the first is the change in production plan that comes outside the database, the second is the alternation in cells, stations, or AGVs such as failures and recoveries, the third also comes from cells, stations, or AGVs such as evidence discrepancy between the estimated machining/transportation time in the scheduling system and the cell/station/AGV. When the trigger is caused by the stations within the cell, the cell controller tries re-scheduling so that the assigned production requirements can be accomplished in the cell[Iriguchi, K., et al., (1992)][Adams, K. G. and Huang, S. H., (1992)].

Figure 3 shows how the actual task takes place when triggers occur. First, the active database sees the job database and picks up the unstarted processes. Then, stations are selected for each of processes. It must be clear that stations are assigned processes according to their abilities which are stored in the station database. Each process is delivered to the selected stations each of them develops the operation plan to estimate the machining time. The estimated machining time by each station is transmitted to the active database. After sometime the gathered information is sent to the scheduling system to generate the production schedule (station assignment ). Because trigger will occur frequently in the actual factories, 
and re-scheduling loads will be heavy, simple rule is adopted here in the scheduling system.

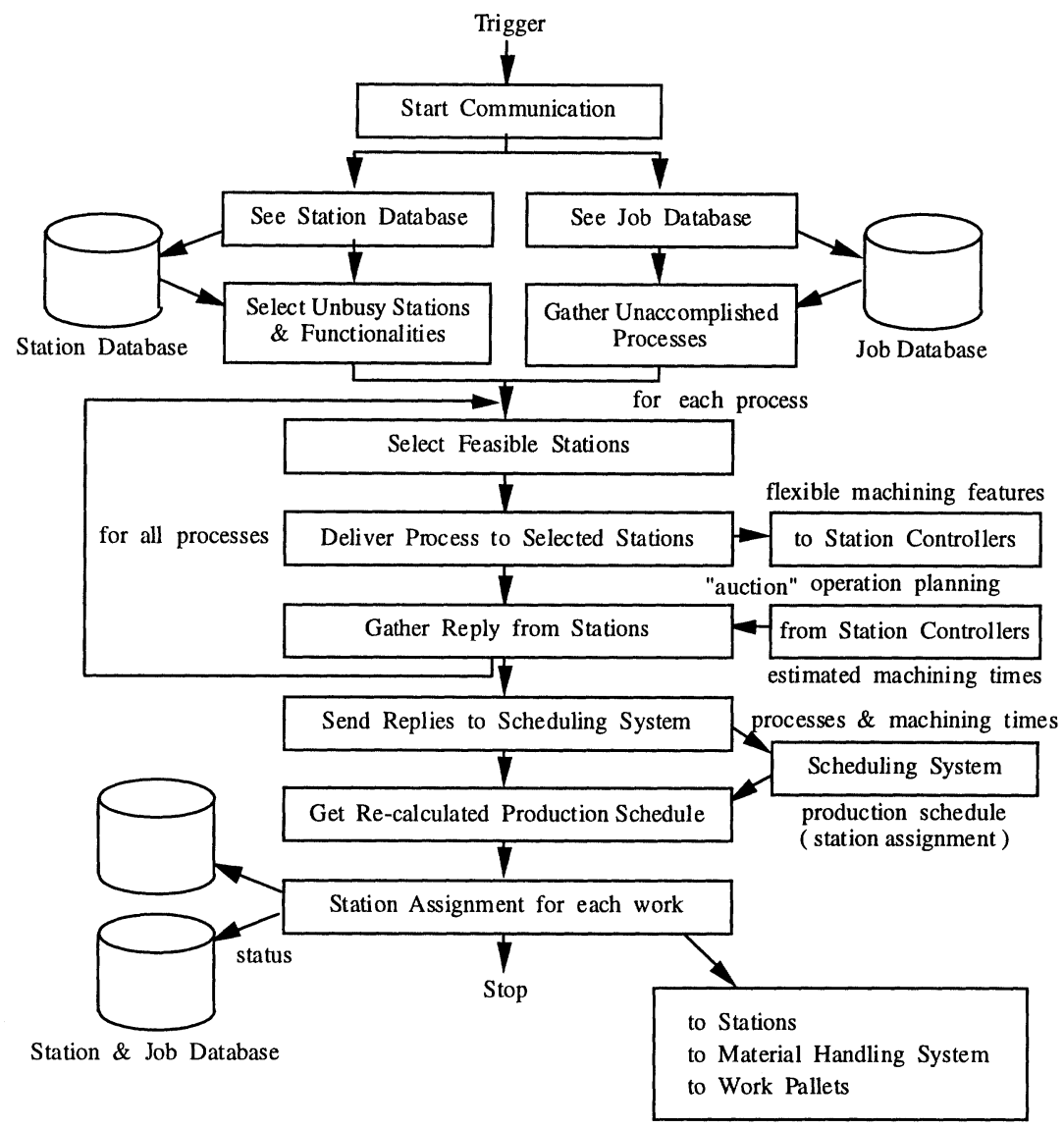

Figure 3 Process flow raised by trigger

The trigger is generated to the active database of the production system from the cell when the re-scheduling within the cell results in unsuccessful. The system tries again re-scheduling for cell assignment.

At this point, "auction" of several consecutive phases takes place, and each phase corresponds to respective removal area. Active database collects the replies, and at each phase probable cells or stations are selected and sent to the scheduling system. After reviewing all necessary phases, selected cells or stations are determined and interwoven into production schedule. 


\section{FLEXIBLE MACHINING FEATURES}

As described in the Section 2, part geometry is characterized by several feasible sets of machining features. In this section, this process is elaborated by showing actual procedure that takes place in CAD/CAM systems[Chang, T. C., (1991)][Arai, E., et al., (1994)].

First, the removal area is computed by making the difference between the blank material and the finished part. The removal area that is composed by the planes and cylinders is decomposed by the cutting planes that are generated referring to the kinds of edges; concave and convex edges.

From any edge, cutting faces can be generated by sweeping the edge along the sweeping directions. The sweeping direction of the edge can be found from the direction of the coordinate system of finished part given by the user. The two connecting faces on the edges considered to generate the cutting face must be plane-plane faces or plane-cylindrical faces. Edges that connecting faces on them are cylindrical faces will not be considered to generate any cutting faces here. The number of generated cutting faces depends on the edge types and the direction of the coordinate system.

An example of this decomposition process is shown in Figure 4. Decomposed removal area can be presented in the And-Or graph such as shown in Figure 5. And nodes in the graph show the decomposed elements. Or nodes show both the resulting of the decomposition and the copy of decomposed elements used in the decomposition process. Leaf nodes in the graph show all decomposed elements found from the root nodes.
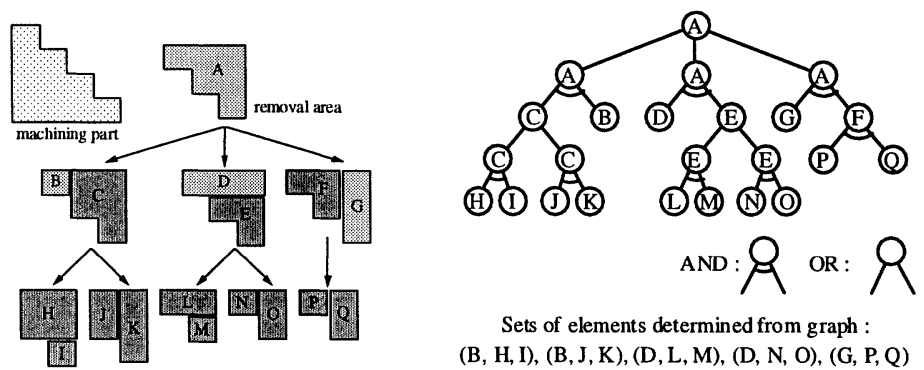

Sets of elements determined from graph : (B, H, I), (B, J, K), (D, L, M), (D, N, O), (G, P, Q)

Figure 4 An example of decom- Figure 5 And-or tree representing decomposition posed elements

Designers can represent their intention about machining parts by use of several types of descriptions such as tolerance and dimensions. Figure 5 show the two 
dimension descriptions of the same part. In Figure 6 (a), it is shown that the hole or slot can be machined without regarding about their machining order because their specifications or positions in the part do not relate with together. But in Figure 6 (b), the hole should have to be machined after the slot because the position of the hole is shown by relating with a face in the slot.

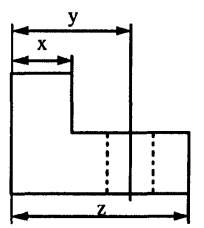

(a)

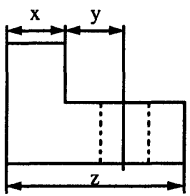

(b)

Figure 6 Two dimension description of the same part

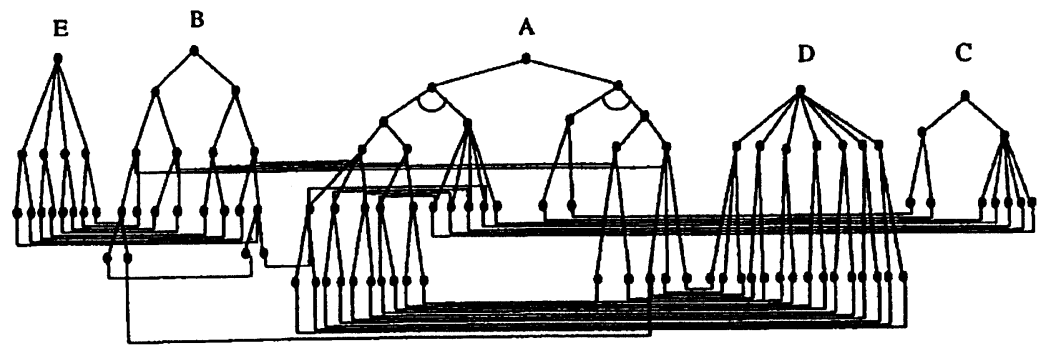

(a) Original and-or graph

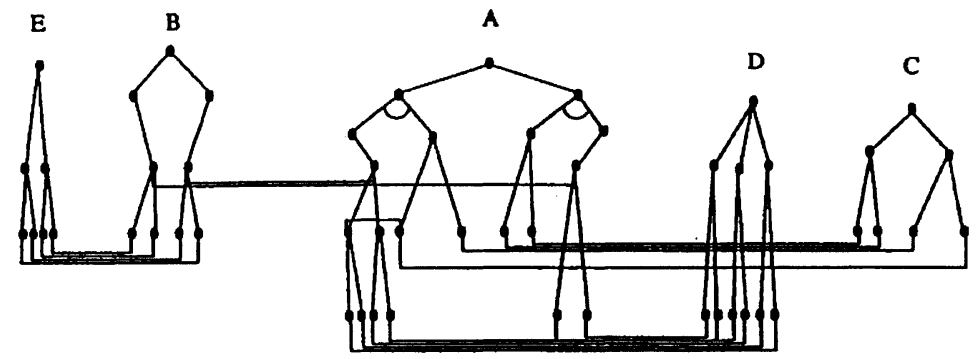

(b) Simplified and-or graph

Figure 7 Two and-or graphs of decomposition 
Since the dimension descriptions of machining parts represent both the specification of parts and the machining orders among machining features in parts, the constraints of machining order considered here as the design intention constraint.

The precedence constraints among machining features can be derived by geometric interference that is detected in the geometric modeling system and attached attributes such as surface roughness.

With taking the precedence constraints into consideration, the number of feasible sets of machining features is reduced, for instance And-Or graph for Figure 7 (a) is simplified as Figure 7 (b). Several sets of machining features for one removal area are generated from the And-Or graph, and are used to present the part shape in the job database.

\section{CASE STUDY}

For more apprehension, in this section a production system with two cells which have 5 stations and 2 AGVs is taken as an example.

When production requirement as Figure 8 is given to the system which has station data shown in Figure 9, production schedule shown in Figure 10 and Figure 11 are generated after executing auction by the active database. In these figures, job $(1,1,1)$ and $(1,1,2)$ are assigned to cell 2 , and job $(2,1,1)$ is assigned to cell 1 . Figure 12 shows the schedule of AGVs.

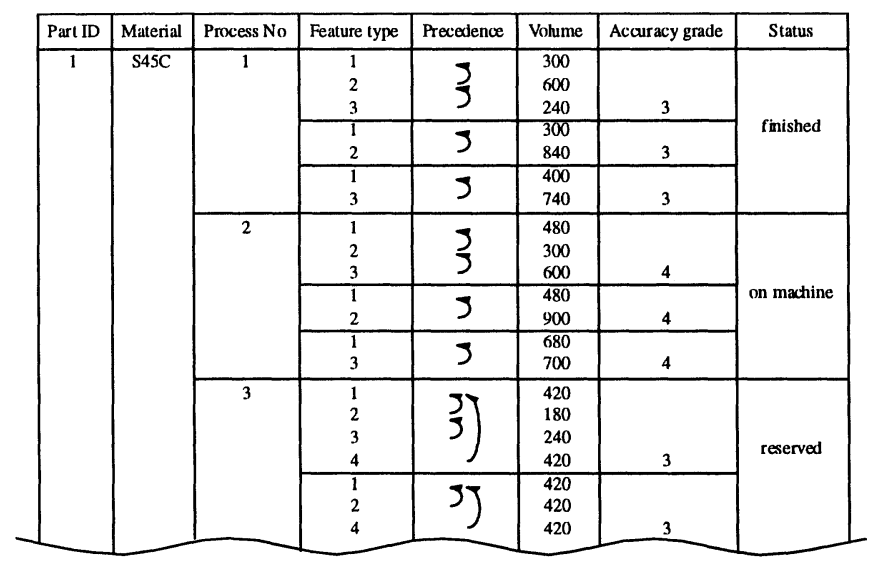

Figure 8 An example of job data 


\begin{tabular}{|c|c|c|c|c|}
\hline $\begin{array}{c}\text { Station } \\
\text { No }\end{array}$ & Status & Possible machining features & Maximum dimensions & $\begin{array}{c}\text { Performance } \\
\text { (cutting volume / min) }\end{array}$ \\
\hline 1 & BUSY & TYPE 1 & $30 \bullet \sim 50$ & 0.04 \\
& $30 \mathrm{~min}$ & TYPE 2 & $30 \bullet \sim 30$ & 0.2 \\
& & TYPE 3 & $10 \bullet \sim 10$ & 0.08 \\
& & TYPE 5 & $20 \bullet \sim 30$ & 0.6 \\
& & TYPE 6 & $20 \bullet \sim 30 \bullet \sim 50$ & 1.2 \\
\hline 2 & FREE & TYPE 3 & $10 \bullet \sim 10$ & 0.05 \\
& $5 \mathrm{~min}$ & TYPE 4 & $40 \bullet \sim 80$ & 0.4 \\
& & TYPE 5 & $30 \bullet \sim 30$ & 1.0 \\
& & TYPE 6 & $30 \bullet \sim 30 \bullet \sim 50$ & 0.08 \\
\hline 3 & TUSY & TYPE 1 & $20 \bullet \sim 20 \bullet \sim 20$ & 0.03 \\
& $25 \mathrm{~min}$ & TYPE 2 & $40 \bullet \sim 60$ & 0.18 \\
& & TYPE 3 & $30 \bullet \sim 40$ & 0.11 \\
\hline
\end{tabular}

Figure 9 An example of station data

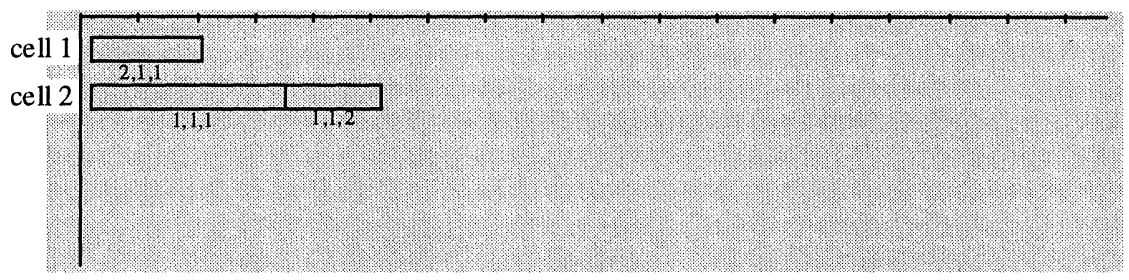

Figure 10 Scheduling result of cells

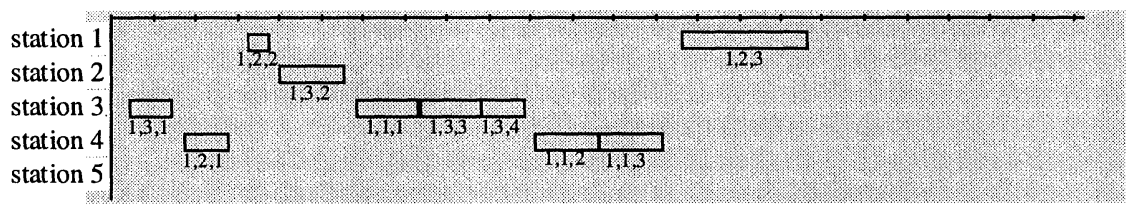

(a) Scheduling result of stations in cell 2 for job $(1,1,1)$

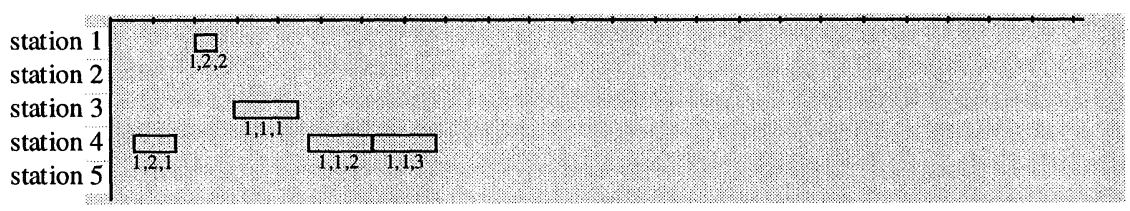

(b) Scheduling result of stations in cell 2 for job $(1,1,2)$ 


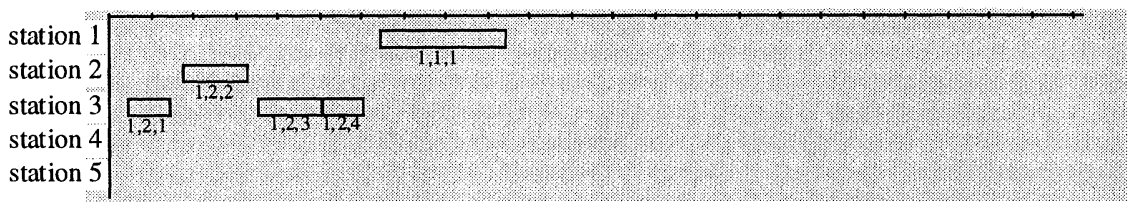

(c) Scheduling result of stations in cell 1 for job $(2,1,1)$

Figure 11 Scheduling results of stations

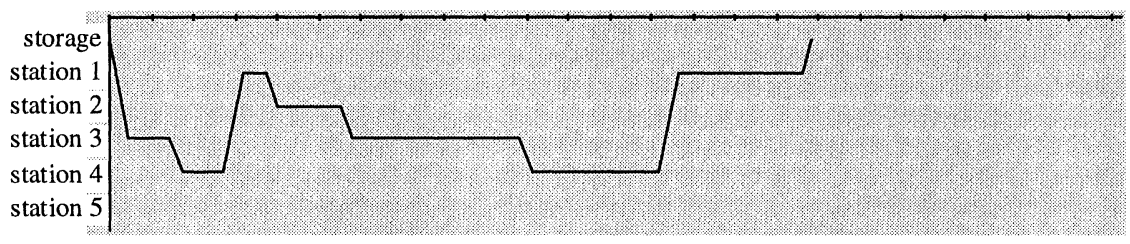

(a) Scheduling result of AGVs in cell 2 for job $(1,1,1)$

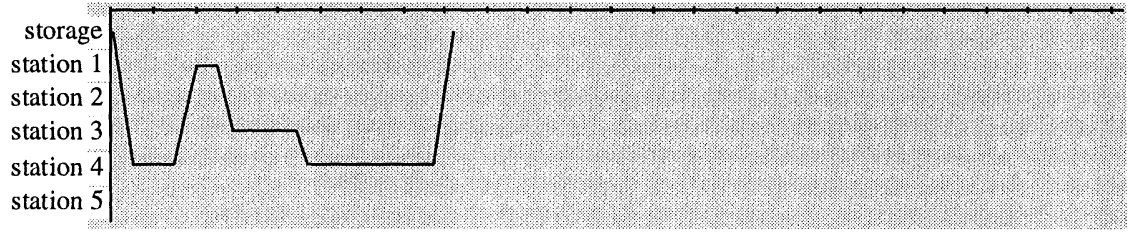

(b) Scheduling result of AGVs in cell 2 for job $(1,1,2)$

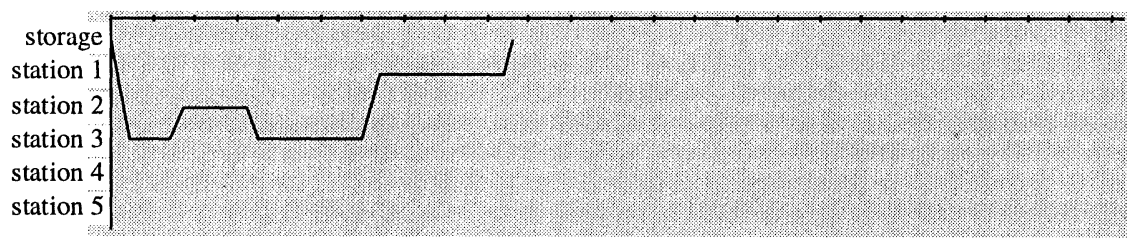

(c) Scheduling result of AGVs in cell 1 for job $(2,1,1)$

Figure 12 Scheduling result of AGVs

\section{CONCLUSION}

In this paper, usability of active database in a distributed production system architecture has been discussed. Active database with auction among cells or 
stations is valuable, for systems can pliably modify the production schedules against various changes in actual production processes. This process will increase ability in production in more flexible ways.

\section{REFERENCES}

Adams, K.G. and Huang, S. H., (1992), “'RTX : A Real-Time Operating System Environment for CNC Machine Tool Control", Prep. of 7th IFAC / IFIP / IFORS /IMACS / ISPE Symposium on Information Control Problems in Manufacturing Technology INCOM '92, Vol. 1, pp. 59-64.

Arai, E. and Amnuay, S. T., (1995), “An Approach to Flexible Cell Assignment and Dynamic Scheduling in FMS", Systems, Control and Information, Vol. 39, No. 10, pp. 549-556.

Arai, E. et al., (1994), "Flexible Process Planning for Autonomous Machining Systems", Proc. of the 2nd Int. Conference on Expert Systems for Development, pp. 216-221.

Chang, T. C., (1991), “Geometric Reasoning - The Key to Integrated Process Planning", Manufacturing Systems, Vol. 20, No. 4, pp. 305-314.

Iriguchi, K., et al., (1992), "'Realtime Tool Path Generation for 5-Axis Control Machining", Proc. of the IMACS/SICE Int. Symposium '92 Kobe, pp. 95-100.

Kjellberg, T., (1991), "Product Modelling - A Tool for Design and Manufacturing System Design, Manufacturing Systems", Vol. 20, No. 4, pp. 315324.

Okino, N., (1992), “A Prototyping of Bionic Manufacturing System", Proc. of Int. Conference on Object-Oriented Manufacturing Systems, pp. 297-302.

Peklenik, J., (1990), “'Development of the Part Spectrum Database for Computer Integrated Manufacturing System", Annals of the C.I.R.P., Vol. 39, No. 1, pp. 471 474.

Ranky, P. G., (1992), 'Intelligent Planning and Dynamic Scheduling of Flexible Manufacturing Cell and Systems", Proc. of the 1992 Japan-U.S.A. Symposium on Flexible Automation, pp. 415-422.

Takata, M., (1995), “'Integrated Environment for Factory Automation", Integrated Computer-Aided Engineering, Vol. 2, No. 4, pp. 249-263.

Ueda, K., (1992), “An Approach to Bionic Manufacturing Systems Based on DNA-Type Information", Proc. of Int. Conference on Object-Oriented Manufacturing Systems, pp. 305-308. 


\section{BIOGRAPHIES}

Eiji Arai: born in 1953.1.15, graduated 1975 Univ. of Tokyo, Dept. of Precision Eng., doctoral course: 1979 Graduated School, Univ. of Tokyo, Dr., Eng. In 1979, Research Associate, Kobe Univ.; In 1983, Associate Prof., Shizuoka Univ.; In 1991, Associate Prof., Tokyo Metropolitan Univ.; In 1995, Prof., Osaka Univ.

Main Research Area includes: (1) Intelligent CAD/CAM Systems for Mechanical Products; Conceptual Design Support, Intention Modeling, Kinematic Simulation, Assembly Planning. (2) Intelligent and Distributed Production System Architecture; Production Process Description, Dynamic Scheduling, Active Database System. (3) Advanced Production Process; Intelligent Welding Machine, Modeling of Deformable Objects.

Masayuki Takata: born in 1959, is an assistant professor at the Univ. of ElectroCommunications, Tokyo, Japan. He is currently studying on infrastructure systems for manufacturing control systems. His research interest includes the real-time manufacturing work-cell controls and the application of the problem solving systems to the real-time control. He received his Dr. Eng. From the Univ. of Tokyo in 1995, on the study of the application of knowledge-base reasoning systems to the real-time control tasks. 